\title{
Resin Infiltration of Fissure Caries with Various Techniques of Pretreatment in vitro
}

\author{
Julian Lausch ${ }^{a}$ Sebastian Paris ${ }^{b}$ Timo Selje ${ }^{c}$ Christof E. Dörfer ${ }^{c}$ \\ Hendrik Meyer-Lueckel ${ }^{a}$ \\ a Department of Operative Dentistry, Periodontology and Preventive Dentistry, RWTH Aachen University, Aachen, \\ ${ }^{b}$ Department of Operative and Preventive Dentistry, Charité-Universitätsmedizin Berlin, Berlin, and ${ }^{\mathrm{C} C l i n i c}$ for \\ Operative Dentistry and Periodontology, Christian-Albrechts-Universität zu Kiel, Kiel, Germany
}

\section{Key Words}

Enamel · Fissure caries · Infiltration · Micro-abrasion

\section{Abstract}

The resin infiltration technique might be used for occlusal caries lesions in order to arrest their progression. This in vitro study evaluated the influence of various modifications of the infiltration technique on the penetration abilities of the infiltrant into occlusal lesions. Extracted human molars and premolars $(n=140)$ with non-cavitated white spot lesions were randomly allocated to 7 groups. As control, specimens were etched with $15 \%$ hydrochloric acid $(\mathrm{HCl})$ gel for $120 \mathrm{~s}$ and resin infiltrated for $180 \mathrm{~s}$ (Icon; DMG). As modification $\mathrm{HCl}$ gel reduced in surface tension and viscosity with and without abrasives was applied using 3 different types of brushes either to oscillate or rub the $\mathrm{HCl}$ gel onto the enamel surface. The median maximum lesion depth was $1,232 \mu \mathrm{m}$ (interquartile range $882-1,513)$. Compared with the control procedure $[23 \%(16 / 50)]$ a higher percentage penetration was observed if the $\mathrm{HCl}$ gel was mixed with a small amount of abrasives were rubbed into the fissures using a modified
(C) 2014 S. Karger AG, Basel

0008-6568/14/0491-0050\$39.50/0 brush with stiff bristles that were adjusted to the fissure relief for either 120 s [100\% (64/100)] or 30 s [98\% (61/100); $p<$ 0.05; Mann-Whitney test]. All other experimental treatments resulted in penetration results in-between. It can be concluded that the use of an abrasive $\mathrm{HCl}$ gel in conjunction with a modified brush mostly enhances resin infiltration into fissure caries lesions.

(c) 2014 S. Karger AG, Basel

The morphology of the fissure relief of human molars and premolars consists of adjacent grooves and fossae [Rohr et al., 1991] that represent the most vulnerable locations to develop dental caries [König, 1963; Macek et al., 2003]. Daily tooth brushing with fluoride toothpaste aims to prevent caries initiation and progression. However, patients often show a lack of compliance with biofilm removal, and self-cleaning of fissures, e.g. by the tongue, does not play a central role as for other tooth surfaces [Splieth et al., 2010]. Thus, fissure sealants are recommended for cariesprone fissures in permanent molars, particularly for patients with increased caries risk [Ahovuo-Saloranta et al.,

\section{KARGER 125}

E-Mail karger@karger.com www.karger.com/cre
Julian Lausch

Department of Operative Dentistry, Periodontology and Preventive Dentistry RWTH Aachen University

Pauwelsstrasse 30, DE-52074 Aachen (Germany)

E-Mail Jlausch@ukaachen.de 
Table 1. Protocol of the various treatments

\begin{tabular}{llll}
\hline Group & Etchant & Time of etching, s & Additional procedure \\
\hline Etch + Inf & Icon etch & 120 & none \\
Etch $_{\mathrm{NB}}+$ Inf & modified etchant & 120 & none \\
Etch $_{\mathrm{OB}}+$ Inf & modified etchant & 120 & oscillating brush for etching \\
Etch $_{\mathrm{OB}}+\mathrm{Inf}_{\mathrm{OB}}$ & & 120 & oscillating brush for etching + infiltration \\
Etch $_{\mathrm{FB}}+$ Inf & modified etchant + abrasives & 120 & flat brush for etching \\
Etch $_{\mathrm{MB} 120}+$ Inf & & 120 & modified brush for etching \\
Etch $_{\mathrm{MB} 30}+\mathrm{Inf}$ & & 30 & modified brush for etching \\
\hline
\end{tabular}

The modified etchant included Icon etch/HCl solution (15\%) (ratio 1:1) and sodium dodecyl sulphate (1\%).

2008; Berger et al., 2010; Simonsen, 2002]. After a pretreatment with phosphoric acid sealants are applied to fill up the fissure relief. They function as a superficial barrier to isolate the enamel surface from the pathogenic biofilm [Griffin et al., 2008; Mejare et al., 2003; Mertz-Fairhurst et al., 1998]. The caries-preventive effect of sealants ranges from a relative risk reduction of $87 \%$ after 12 months to about $60 \%$ after $48-54$ months [Ahovuo-Saloranta et al., 2008] depending on the retention of the sealant [Mejare et al., 2003]. Furthermore, sealants function as a barrier for fermentable carbohydrates to avoid glycolysis by bacteria within the lesion [Mertz-Fairhurst et al., 1998] and seem to delay lesion progression if placed on caries lesions [Splieth et al., 2010]. However, they usually penetrate only superficially into caries lesions [Paris et al., 2014].

In contrast to fissure sealing with the resin infiltration technique, deep penetration of infiltrants into enamel caries lesions can be achieved. Hereby, a diffusion barrier not on the enamel surface but inside the lesion body is created [Meyer-Lueckel and Paris, 2008]. In proximal lesions a relatively high mineralized surface layer $(\leq 50 \mu \mathrm{m}$ thickness) covers the porous lesion body and therefore inhibits resin penetration [Meyer-Lueckel et al., 2007]. It has been shown that pretreatment with $15 \%$ hydrochloric acid $(\mathrm{HCl})$ gel removed up to $70 \%$ of surface layers [Meyer-Lueckel et al., 2007]. It has been argued that also 37\% phosphoric acid $\left(\mathrm{H}_{3} \mathrm{PO}_{4}\right)$ gel frequently used for adhesive purposes could be effective to erode the surface layer of rather active proximal lesions [Neuhaus et al., 2012]. Nonetheless, pretreatment with $15 \% \mathrm{HCl}$ gel for $2 \mathrm{~min}$ allows a more complete erosion of the surface layer [Meyer-Lueckel et al., 2007] resulting in an almost complete penetration of the infiltrant into proximal lesions [Meyer-Lueckel and Paris, 2010].

Resin Penetration into Fissure Caries Lesions
In contrast to proximal caries only a negligible penetration of infiltrants into fissure caries lesions could be achieved after etching with $37 \% \mathrm{H}_{3} \mathrm{PO}_{4}$ gel [11\% (0/20)]. The use of $15 \% \mathrm{HCl}$ gel resulted in a higher but still incomplete penetration of occlusal lesions [41\% (30/78)] [Paris et al., 2014]. Possibly, due to air bubbles, calculus remnants and residual biofilm, the acid was not capable of reaching the lesion parts situated in pits and fissures. Consequently, the highly mineralized surface layer was not eroded sufficiently, resulting in rather low penetration depths [Paris et al., 2014].

Thus, the aim of the present study was to compare the penetration depths of an infiltrant after different pretreatment procedures using $15 \% \mathrm{HCl}$ gel. We hypothesized that these modifications would lead to a significantly deeper and more complete penetration of the infiltrant into non-cavitated caries lesions situated in fissure areas compared with the standard infiltration technique.

\section{Materials and Methods}

\section{Specimen Selection}

Extracted human molars and premolars $(n=140)$ with active, non-cavitated white spot lesions (ICDAS-2; dull surface, chalky opacity) were graduated by 2 trained and calibrated examiners (S.P., J.L.) according to the International Caries Detection and Assessment System (ICDAS) [Ismail et al., 2007]. In case of disagreement a consensus rank was agreed. The study protocol conformed to the principles outlined in the German Ethics Committee's statement for the use of human body material in medical research [Central German Ethics Committee, 2003].

\section{Treatment}

The groups as well as the different treatment protocols are shown in table 1 . As control, the fissure systems were etched with $15 \% \mathrm{HCl}$ gel [Icon etch (Etch); DMG, Hamburg, Germany] for 
Fig. 1. Pictures of the 3 different brushes $(\mathbf{a}-\mathbf{c})$ that were used in this study: relatively long and flexible bristles of a batterydriven oscillating brush (a) vibrated the $\mathrm{HCl}$ gel or the infiltrant. The conventional flat brush (b) seemed not to reach deeper parts of the fissure relief, whereas the rather stiff bristles (differing in length) of the modified brush (c) seemed to rub the $\mathrm{HCl}$ gel on the enamel surface even in the fundus area. d Representative image of an infiltrated fissure caries lesion $\left(\right.$ Etch $_{\mathrm{MB} 120}+$ Inf). The infiltrant (red) penetrated into the porous lesion body (green = non-infiltrated; colours in the online version only).
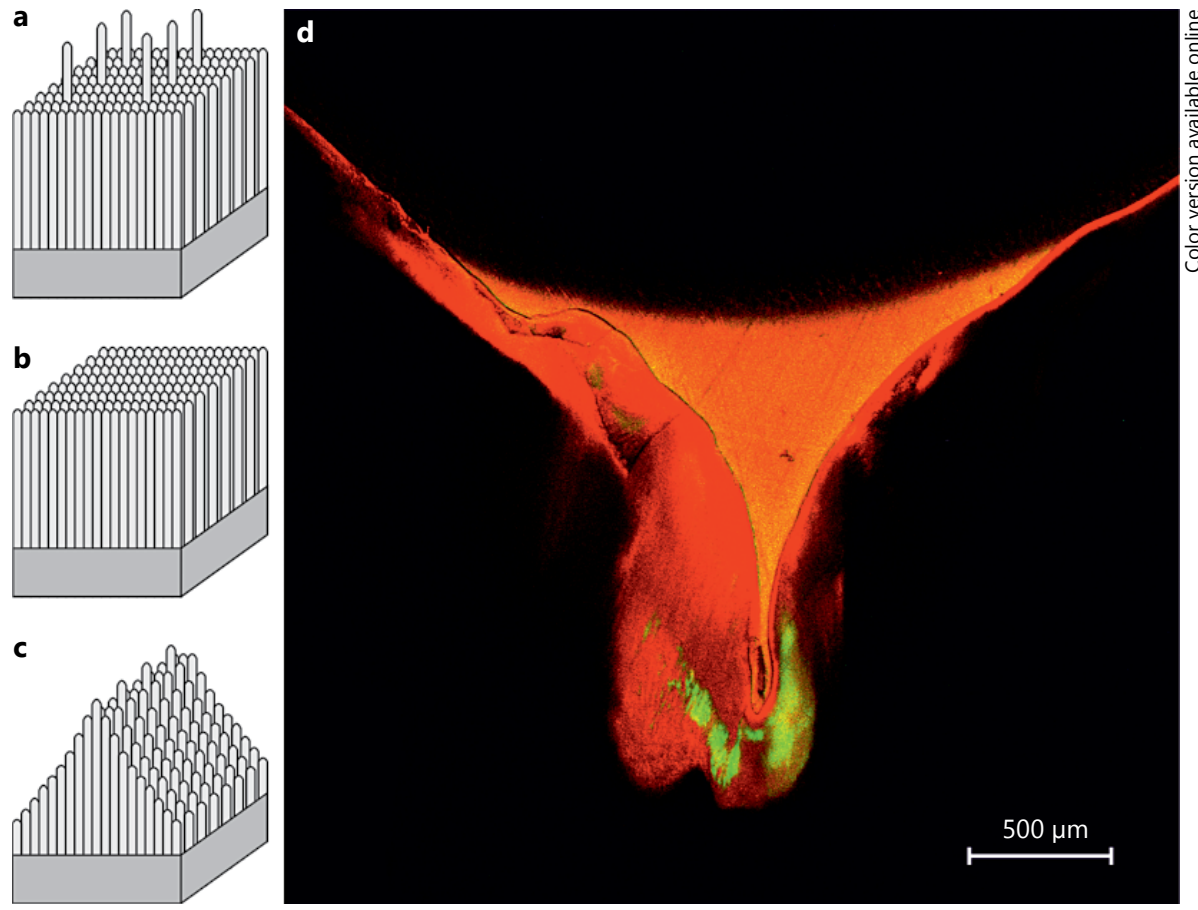

$120 \mathrm{~s}$ and rinsed for $30 \mathrm{~s}$ (group: Etch + Inf). Furthermore, a modified etchant [addition of $1 \%$ sodium dodecyl sulphate and a mixture with $15 \% \mathrm{HCl}$ solution (1:1)] was used (group: $\mathrm{Etch}_{\mathrm{NB}}+\mathrm{Inf}$ ). The modified etchant was moved within the fissures using an oscillating brush (Dr. Best Vibration Zwischenzahn; GSK, Bühl, Germany; fig. 1a; groups: Etch $_{\mathrm{OB}}+$ Inf, $\mathrm{Etch}_{\mathrm{OB}}+\operatorname{Inf}_{\mathrm{OB}}$ ) or the modified etchant, additionally mixed with $2 \%$ pumice (abrasives), was rubbed (manually by the examiner J.L.) preferably within the fissure relief on the enamel surface. Thereby, a flat brush (group: Etch $_{\mathrm{FB}}$ + Inf; Dr. Best Plus; GSK; fig. 1b) or a modified toothbrush were used (group: Etch ${ }_{\mathrm{MB} 120}+$ Inf; Dr. Best X-Zwischenzahn; GSK; fig. 1c). Additionally, in one group the time of etching was shortened from 120 to $30 \mathrm{~s}$ (group: $\mathrm{Etch}_{\mathrm{MB} 30}+\mathrm{Inf}$ ). After pretreatment all specimens were stored in $0.1 \%$ ethanolic solution of tetramethylrhodamine isocyanate (RITC; Sigma Aldrich, Steinheim, Germany) for $24 \mathrm{~h}$ and afterwards carefully dried with compressed air (10 s). The infiltrant [Icon infiltrant (Inf); DMG] was labeled with RITC and applied for $180 \mathrm{~s}$ either with $\left(\mathrm{Etch}_{\mathrm{OB}}+\operatorname{Inf}_{\mathrm{OB}}\right)$ or without (all other groups) the oscillating brush. Afterwards, the infiltrant was hardened with blue light for $60 \mathrm{~s}\left(530 \mathrm{~mW} / \mathrm{cm}^{2}\right.$; Astralis 5; Ivoclar Vivadent, Ellwangen, Germany).

The roots of the teeth were removed (Band Saw 300cl; Exact Apparatebau, Norderstedt, Germany) and the specimens were embedded (Technovit; Heraeus Kulzer, Wehrheim, Germany). To create slices of approximately 1,200 $\mu \mathrm{m}$ thickness, teeth were cut across perpendicularly to the lesion surface (Band Saw 300cl; Exact Apparatebau). The specimens were fixed on a microscope slide (Locite 493; Henkel, Munich, Germany) and polished to $1,000 \mu \mathrm{m}$ thickness $( \pm 20 \mu \mathrm{m}$; Mikroschleifsystem 400cs; Abrasive Paper 1,200, 2,400, 4,000, Exact Apparatebau). Unbound red fluorophore RITC was bleached by immersion of the specimens in
$30 \%$ hydrogen peroxide for $12 \mathrm{~h}$. Then, the non-infiltrated porous structures of the lesion were counterstained with $50 \%$ ethanol solution of $100 \mu \mathrm{M}$ sodium fluorescein (Sigma Aldrich) for 3 min. Finally, the specimens were rinsed with deionized water for $10 \mathrm{~s}$.

\section{Image Analysis}

Specimens were observed using dual fluorescence and confocal laser scanning microscopy (Carl Zeiss, Jena, Germany; $5 \times$ objective) [Paris et al., 2009]. Multiple images of $1,024 \times 1,024 \mu \mathrm{m}$ were combined with the help of graphic software (Photoshop Elements 6; Adobe Systems GmbH, Munich, Germany).

\section{Measurement}

Lesion depths and penetration depths were measured from the enamel surface to the deepest point of green or red fluorescence, respectively. Lesion and penetration depth were both measured at 18 defined points (9-point measurement on each side of the fissure) along the enamel prisms (Axiovision; Carl Zeiss) [Paris et al., 2014].

\section{Statistical Analysis}

Data were checked for normal distribution (Shapiro-Wilk test). We analysed the lesion depth $\left(\mathrm{LD}_{\max }\right)$ and penetration depth $\left(\mathrm{PD}_{\max }\right)$ at the deepest lesion side as well as the average lesion depth $\left(\mathrm{LD}_{\mathrm{av}}\right)$ and penetration depth $\left(\mathrm{PD}_{\mathrm{av}}\right)$ for each specimen (KruskalWallis test).

Percentage penetration $\left(\mathrm{PP}_{\max }\right)$ was calculated as $\mathrm{PP}_{\max }=$ $\mathrm{PD}_{\max } / \mathrm{LD}_{\max } \times 100$ and compared between the various treatments by Mann-Whitney tests. To minimize the limiting influence of (low) lesion and penetration depth, subset analyses of $\mathrm{PD}_{\max 500}$ 
Table 2. Medians ( $\mu \mathrm{m}$; interquartile ranges in parentheses) of the mean lesion $\left(\mathrm{LD}_{\mathrm{av}}\right)$ and penetration depths $\left(\mathrm{PD}_{\mathrm{av}}\right.$; each $18 \mathrm{measure}$ ments) as well as the maximum lesion depths $\left(\mathrm{LD}_{\max }\right)$ and penetration depths at $\mathrm{LD}_{\max }\left(\mathrm{PD}_{\max }\right)$ of the 7 treatments for all lesions and for lesions with $\mathrm{LD}_{\max }>500 \mu \mathrm{m}$

\begin{tabular}{|c|c|c|c|c|c|c|c|c|}
\hline Groups & \multicolumn{5}{|c|}{ All lesions } & \multicolumn{3}{|c|}{ Lesions with $\mathrm{LD}_{\max }>500 \mu \mathrm{m}$} \\
\hline Etch $+\operatorname{Inf}$ & 17 & $723(405-876)$ & $146(118-338)^{\mathrm{a}, \mathrm{b}}$ & $1,248(916-1,472)$ & $234(116-491)^{\mathrm{a}, \mathrm{b}}$ & 16 & $1,254(974-1,493)$ & $261(147-622)^{\mathrm{a}, \mathrm{b}}$ \\
\hline $\mathrm{Etch}_{\mathrm{NB}}+\operatorname{Inf}$ & 18 & $746(573-977)$ & $123(80-235)^{\mathrm{a}}$ & $1,392(1,168-1,690)$ & $176(75-371)^{\mathrm{a}}$ & 17 & $1,470(1,184-1,690)$ & $174(75-371)^{\mathrm{a}}$ \\
\hline $\mathrm{Etch}_{\mathrm{OB}}+\operatorname{Inf}$ & 15 & $619(418-919)$ & $322(189-544)^{\mathrm{b}}$ & $1,185(959-1,558)$ & $459(272-891)^{\mathrm{b}}$ & 13 & $1,214(978-1,558)$ & $503(272-891)^{\mathrm{b}}$ \\
\hline $\operatorname{Etch}_{\mathrm{OB}}+\operatorname{Inf}_{\mathrm{OB}}$ & 17 & $547(264-823)$ & $181(137-289)^{\mathrm{a}, \mathrm{b}}$ & $1,288(700-1,496)$ & $320(190-633)^{\mathrm{a}, \mathrm{b}}$ & 15 & $1,304(828-1,515)$ & $304(159-667)^{\mathrm{a}, \mathrm{b}}$ \\
\hline $\operatorname{Etch}_{\mathrm{MB} 30}+\operatorname{Inf}$ & 20 & $667(527-842)$ & $500(345-704)^{\mathrm{c}}$ & $1,244(1,004-1,556)$ & $963(758-1,324)^{c}$ & 20 & $1,244(1,004-1,556)$ & $963(758-1,324)^{\mathrm{c}}$ \\
\hline
\end{tabular}

Different superscript letters indicate statistically significant differences $(\mathrm{p}<0.05$; Mann-Whitney test) between the treatments; for results without any superscript letters, no significant differences were observed $(p>0.05) . n=$ Sample size per group.

and $\mathrm{PP}_{\max 500}$ values for lesions having a maximum lesion depth $>500 \mu \mathrm{m}\left(\mathrm{LD}_{\max 500}\right)$, were performed (Mann-Whitney test). The level of significance was set at $5 \%$ for all tests (SPSS version 20.0; Munich, Germany).

\section{Results}

The confocal laser scanning microscopy images showed the penetration of the infiltrant (red fluorescence) into the porous lesion body (green fluorescence; fig. 1d) that was most pronounced after abrading the surface layer using the respective brush. No cavitation of the enamel surface could be observed for any of the treatments.

Overall, 17 lesions were judged as being too shallow $\left(\mathrm{LD}_{\max }<200 \mu \mathrm{m}\right)$ or destroyed during confocal laser scanning microscopy preparation and therefore excluded. The median $\mathrm{LD}_{\max }(\mathrm{n}=123)$ and $\mathrm{LD}_{\max 500}(\mathrm{n}=116)$ were $1,232 \mu \mathrm{m}$ (interquartile range $882-1,513$ ) and $1,270 \mu \mathrm{m}$ (971-1,530), respectively. No significant differences in lesion depth between the various groups were observed ( $p$ > 0.05; Kruskal-Wallis test; table 2).

Micro-abrasive treatments $\left(\mathrm{Etch}_{\mathrm{MB} 120}+\mathrm{Inf}_{\mathrm{Etch}} \mathrm{EtB}_{\mathrm{MB}}+\right.$ Inf) resulted in the highest $\mathrm{PD}_{\max }$ compared with all other treatments being significantly different compared with the control group (Etch + Inf; $\mathrm{p}<0.05)$. Similar results were evaluated for $\mathrm{PD}_{\max 500}$ (table 2).

Analysis of $\mathrm{PD}_{\max }$ (1-point measurement) and $\mathrm{PD}_{\mathrm{av}}$ (multiple measurements) revealed similar results (table 2).

$\mathrm{PP}_{\max 500}$ values of the various groups are shown in figure 2. An almost complete penetration was observed for
$\mathrm{Etch}_{\mathrm{MB} 120}+\mathrm{Inf}$ and $\mathrm{Etch}_{\mathrm{MB} 30}+\mathrm{Inf}$, not being significantly different from each other ( $p>0.05$; Mann-Whitney test), but both being significantly higher compared with the other 5 treatments $(\mathrm{p}<0.05)$.

\section{Discussion}

In the present study, the infiltrant was capable to penetrate several hundred micrometres into fissure caries lesions. This corroborates findings for proximal lesions [Meyer-Lueckel and Paris, 2010; Soviero et al., 2012]. The study hypothesis that modifications of the pretreatment would lead to a significantly enhanced and almost complete infiltration into occlusal lesions could only partially be confirmed, since a modified $\mathrm{HCl}$ gel $\left(\mathrm{Etch}_{\mathrm{NB}}+\mathrm{Inf}\right)$ alone could not improve the penetration abilities of the infiltrant. Oscillation of the $\mathrm{HCl}$ gel or the infiltrant $\left(\right.$ Etch $\left._{\mathrm{OB}}+\operatorname{Inf}, \mathrm{Etch}_{\mathrm{OB}}+\operatorname{Inf}_{\mathrm{OB}}\right)$ or micro-abrasion with a normal flat brush $\left(\mathrm{Etch}_{\mathrm{FB}}+\mathrm{Inf}\right)$ enhanced penetration. But only with micro-abrasive pretreatments using a modified brush $\left(\mathrm{Etch}_{\mathrm{MB} 120}+\mathrm{Inf}\right.$, $\mathrm{Etch}_{\mathrm{MB} 30}+$ Inf) fissure caries lesions were infiltrated almost completely.

Previous studies argued that the measurement of the infiltrated area reflects penetration abilities of an infiltrant better compared with a 1-point measurement [Neuhaus et al., 2012; Soviero et al., 2012]. In the present study penetration was evaluated by both a 1-point measurement at the deepest lesion site as well as by mean values of a multiple-point measurement. As with area measurements, mean values include shallow parts of the lesion $(<500 \mu \mathrm{m})$ as well. Since these parts should be penetrated 


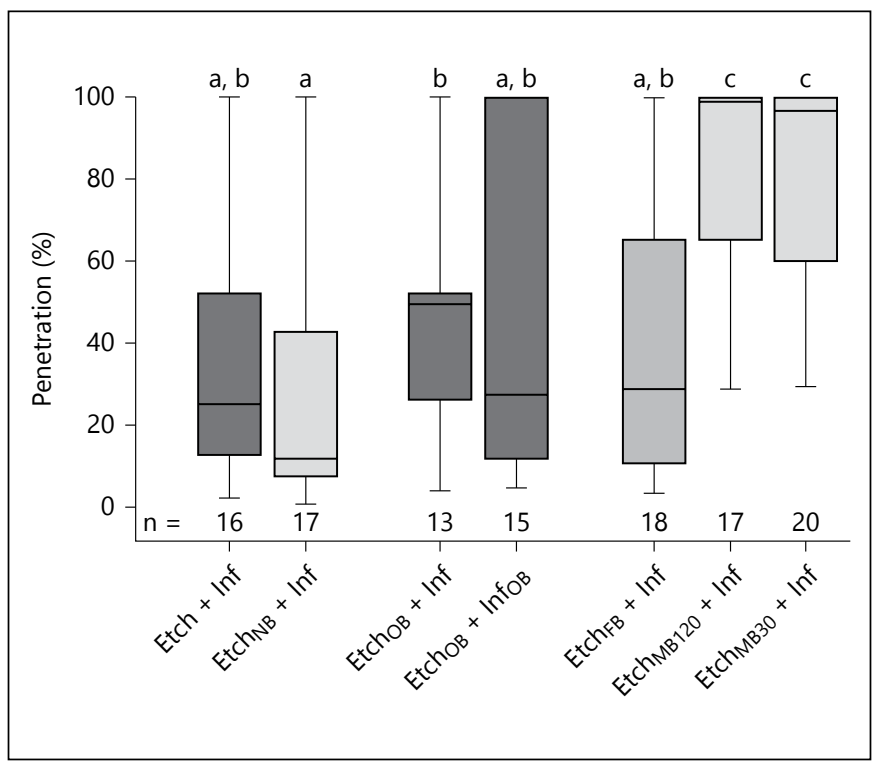

Fig. 2. Percentage penetration $\left(\mathrm{PP}_{\max 500}\right.$; box and thick line $=25$ th and 75 th percentile and median, error bars $=$ minima and maxima) of the infiltrant (Inf) into lesions with $\mathrm{LD}_{\max }>500 \mu \mathrm{m}$ for the various treatments $\left(\right.$ Etch $=$ etchant, $\mathrm{Inf}=$ infiltrant, Etch $_{\mathrm{NB}}+\mathrm{Inf}=$ no brush, Etch ${ }_{\mathrm{OB}}+$ Inf, Etch OB $_{\mathrm{O}}+\operatorname{Inf}_{\mathrm{OB}}=$ oscillating brush, Etch $_{\mathrm{FB}}+$ Inf = flat brush, Etch $_{\mathrm{MB} 120}+\mathrm{Inf}=$ modified brush for $120 \mathrm{~s}$, $\mathrm{Etch}_{\mathrm{MB} 30}+\mathrm{Inf}=$ modified brush for $30 \mathrm{~s}$ ). Use of abrasives and a special brush (Etch $\left.{ }_{\mathrm{MB} 120}+\mathrm{Inf}, \mathrm{Etch}_{\mathrm{MB} 30}+\mathrm{Inf}\right)$ led to almost complete penetration. Statistically significant differences between various treatment groups are indicated by different letters $(p<0.05$; Mann-Whitney test). $\mathrm{n}=$ Number of teeth.

rather completely [Meyer-Lueckel and Paris, 2010], the 1-point measurement seems to be more eligible to describe the maximum penetration abilities of an infiltrant. However, in the present investigation both measurements revealed similar outcomes.

It has been shown that $\mathrm{HCl}$ gel is capable of eroding the surface layer of proximal caries lesions [Meyer-Lueckel et al., 2007]. However, due to its rather high viscosity, conventional $\mathrm{HCl}$ gel might not have reached occlusal lesions situated within deeper parts of the fissure resulting in a rather shallow lesion infiltration [Paris et al., 2014]. Furthermore, it was assumed that even if $\mathrm{HCl}$ gel reaches deeper areas within fissures, enamel surfaces might only be insufficiently wetted due to rather high surface tension of the $\mathrm{HCl}$ gel. Consequently, we reduced the viscosity and surface tension of the $\mathrm{HCl}$ gel; nonetheless, these modifications could not improve infiltration properties considerably.

Possibly, air bubbles within the fissure hampered the $\mathrm{HCl}$ gel (and also the infiltrant) to reach the lesion areas particularly in deep fissures [Asmussen, 1977; Paris et al., 2014]. To remove these air bubbles, the etchant as well as the infiltrant were applied with the help of an oscillating brush. This procedure led to enhanced but compared with proximal lesions still relatively low penetration depths [Paris et al., 2011]. Probably, air bubbles were destroyed, but the oscillation was not capable of eroding the surface layer sufficiently in order to improve resin infiltration considerably.

Contrary to the other treatments, abrasion of the enamel surface by using a modified brush and abrasive etching gel allowed an almost complete infiltration. Studies on micro-abrasion techniques showed enhanced erosion when an $\mathrm{HCl}$ gel pumice slurry was applied with a rotating rubber cup $(360 \pm 130 \mu \mathrm{m})$ compared with $\mathrm{HCl}$ gel application alone $(100 \pm 47 \mu \mathrm{m})$ [Tong et al., 1993] although this effect also depends on the force used. The erosion of the enamel surface layer was not measured directly in the present study but as a result after a rather abrasive pretreatment the penetration depths were significantly higher. It seems that the hard bristles of the modified brush (bristles differing in lengths) combined with $\mathrm{HCl}$ gel pumice slurry removed air bubbles as well as calculus remnants and therefore eroded the highly mineralized surface layer sufficiently.

Nonetheless, micro-abrasion techniques also involve the risk of cavity formation of the enamel surface that would change a lesion from ICDAS-2 to ICDAS-3 (cavitated in enamel). Fortunately, no cavitation could be observed in the present investigation for the various pretreatments.

Resin penetration seems to depend on the mode of etching [Neuhaus et al., 2012; Paris et al., 2014] and shorter etching times should result in less erosion of the surface layer. However, for the treatment of fissure caries the combination of abrasives with $\mathrm{HCl}$ gel allowed an almost complete penetration of the infiltrant, even if the time of etching was reduced to $30 \mathrm{~s}$.

In clinical practice a careful handling with $\mathrm{HCl}$ gel should be recommended because even short exposures to $\mathrm{HCl}$ gel $(\geq 30 \mathrm{~s})$ might evoke ulcerations of the gingiva [Croll et al., 1990]. However, if a rubber dam is applied to avoid contact of acid with soft tissues, the use of $\mathrm{HCl}$ gel seems to be safe. It is still unclear how much of the surface layer has to be eroded for a sufficient infiltration to hamper further caries progression. Nonetheless, for clinical practice short application of a small amount of $\mathrm{HCl}$ gel is advantageous, especially for the treatment of children.

In conclusion, the use of the conventional infiltration technique for proximal and smooth surface lesions seems 
to result in lower penetration depths when used for fissure caries lesions. A more liquid $\mathrm{HCl}$ gel as well as oscillation of the etchant could not considerably enhance resin penetration. Micro-abrasion of the enamel surface by a modified brush and abrasive $\mathrm{HCl}$ gel slurry resulted in a nearly complete infiltration and therefore appears to be most suitable for pretreatment of occlusal caries lesions situated in fissures.

\section{Acknowledgements}

The authors are indebted to Mr. Michael Stiebritz for his most valuable contribution to the present investigation. This study was supported by the Deutsche Forschungsgemeinschaft (DFG; PA 1508/1-3).

\section{Author Contributions}

H.M.-L. and S.P. designed and J.L. planned the study; J.L. and T.S. prepared the samples; J.L. performed the measurements and statistical analysis; J.L. wrote the manuscript. H.M.-L. and S.P. commented on, and all authors revised the manuscript. The results of this paper have been also published in form of the doctoral thesis of J.L. at RWTH Aachen University.

\section{Disclosure Statement}

The Charité Universitätsmedizin Berlin holds patents for an infiltration technique for dental caries lesions in which two of the authors (S.P. and H.M.-L.) are appointed as inventors. These patents have been licensed by the DMG, Hamburg, Germany. S.P. and H.M.-L. receive royalties from this license as well as a research grant from the DMG. J.L. receives a research grant from the DMG.

\section{References}

Ahovuo-Saloranta A, Hiiri A, Nordblad A, Makela M, Worthington HV: Pit and fissure sealants for preventing dental decay in the permanent teeth of children and adolescents. Cochrane Database Syst Rev 2008;4:CD001830.

-Asmussen E: Penetration of restorative resins into acid etched enamel. II. Dissolution of entrapped air in restorative resin monomers. Acta Odontol Scand 1977;35:183-191.

- Berger S, Goddon I, Chen CM, Senkel H, Hickel R, Stosser L, Heinrich-Weltzien R, Kuhnisch J: Are pit and fissure sealants needed in children with a higher caries risk? Clin Oral Invest 2010;14:613-620.

Central German Ethics Committee: The use of human body materials for the purposes of medical research (in German). 2003. http:// www.zentrale-ethikkommission.de/page. asp?his=0.1.21.

Croll TP, Killian CM, Miller AS: Effect of enamel microabrasion compound on human gingiva: report of a case. Quint Int 1990;21:959-963.

- Griffin SO, Oong E, Kohn W, Vidakovic B, Gooch
BF, Group CDCDSSRW, Bader J, Clarkson J, Fontana MR, Meyer DM, Rozier RG, Weintraub JA, Zero DT: The effectiveness of sealants in managing caries lesions. J Dental Res 2008;87:169-174.

- Ismail AI, Sohn W, Tellez M, Amaya A, Sen A, Hasson H, Pitts NB: The International Caries Detection and Assessment System (ICDAS): an integrated system for measuring dental caries. Community Dent Oral Epidemiol 2007;35:170-178.
König KG: Dental morphology in relation to caries resistance with special reference to fissures as susceptible areas. J Dental Res 1963;2:461476.

Macek MD, Beltran-Aguilar ED, Lockwood SA, Malvitz DM: Updated comparison of the caries susceptibility of various morphological types of permanent teeth. J Public Health Dent 2003;63:174-182.

Mejare I, Lingstrom P, Petersson LG, Holm AK, Twetman S, Kallestal C, Nordenram G, Lagerlof F, Soder B, Norlund A, Axelsson S, Dahlgren $\mathrm{H}$ : Caries-preventive effect of fissure sealants: a systematic review. Acta Odontol Scand 2003;61:321-330.

Mertz-Fairhurst EJ, Curtis JW Jr, Ergle JW, Rueggeberg FA, Adair SM: Ultraconservative and cariostatic sealed restorations: results at year 10. J Am Dent Assoc 1998;129:55-66.

Meyer-Lueckel H, Paris S: Improved resin infiltration of natural caries lesions. J Dent Res 2008;87:1112-1116.

Meyer-Lueckel H, Paris S: Infiltration of natural caries lesions with experimental resins differing in penetration coefficients and ethanol addition. Caries Res 2010;44:408-414.

Meyer-Lueckel H, Paris S, Kielbassa AM: Surface layer erosion of natural caries lesions with phosphoric and hydrochloric acid gels in preparation for resin infiltration. Caries Res 2007;41:223-230.

Neuhaus KW, Schlafer S, Lussi A, Nyvad B: Infiltration of natural caries lesions in relation to their activity status and acid pretreatment in vitro. Caries Res 2012;47:203-210.
Paris S, Bitter K, Naumann M, Dörfer CE, MeyerLueckel H: Resin infiltration of proximal caries lesions differing in ICDAS codes. Eur J Oral Sci 2011;119:182-186.

Paris S, Bitter K, Renz H, Hopfenmüller W, Meyer-Lueckel H: Validation of two dual fluorescence techniques for confocal microscopic visualization of resin penetration into enamel caries lesions. Microsc Res Tech 2009;72:489_ 494.

Paris S, Lausch J, Selje T, Dörfer CE, Meyer-Lueckel H: Comparison of sealant and infiltrant penetration into pit and fissure caries lesions in vitro. J Dent 2014;42:432-438.

Rohr M, Makinson OF, Burrow MF: Pits and fissures: morphology. ASDC J Dent Child 1991; 58:97-103.

Simonsen RJ: Pit and fissure sealant: review of the literature. Pediatr Dent 2002;24:393-414.

Soviero VM, Paris S, Leal SC, Azevedo RB, MeyerLueckel $\mathrm{H}$ : Ex vivo evaluation of caries infiltration after different application times in primary molars. Caries Res 2012;47:110-116.

Splieth CH, Ekstrand KR, Alkilzy M, Clarkson J, Meyer-Lueckel H, Martignon S, Paris S, Pitts NB, Ricketts DN, van Loveren C: Sealants in dentistry: outcomes of the Orca Saturday Afternoon Symposium 2007. Caries Res 2010; 44:3-13.

Tong LS, Pang MK, Mok NY, King NM, Wei SH: The effects of etching, micro-abrasion, and bleaching on surface enamel. J Dent Res 1993; 72:67-71.
Resin Penetration into Fissure Caries Lesions 